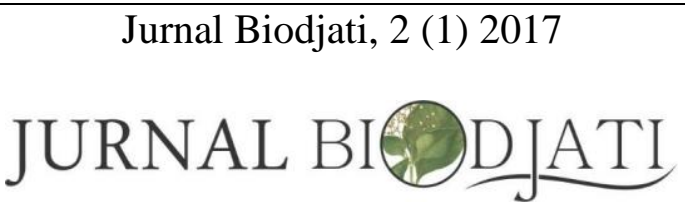

http://journal.uinsgd.ac.id/index.php/biodjati

\title{
EFEKTIVITAS PENYIANGAN TERHADAP HASIL TANAMAN WORTEL (Daucus carota L.) LOKAL CIPANAS BOGOR
}

\author{
Enceng Sobari ${ }^{1}$, Ferdi Fathurohman ${ }^{2}$
}

\author{
1,2 Program Studi Agroindustri, Politeknik Negeri Subang
}

Diterima 23 April 2017

Disetujui 28 Mei 2017

Publish 31 Mei 2017

Korespondensi :

Jl. Arief Rahman Hakim No. 8

(Islamic Center) Cigadung

Subang Jawa Barat 41212, Telp

: (0260) 417648, Fax : (0260)

417628

e-mail:

encengsobari@polsub.ac.id

e-ISSN : 2541-4208

p-ISSN : 2548-1606
Abstrak. Potensi tanaman lokal di Indonesia sebagai bahan konsumsi pangan memiliki peranan penting. Wortel merupakan sayuran yang memiliki peranan penting dalam penyediaan bahan pangan bagi manusia. Sayuran wortel sebagai sumber vitamin A, digunakan sebagai bahan baku kosmetik dan memiliki khasiat obat karena kandungan beta karoten. Rendahnya hasil produksi wortel dapat disebabkan teknik budidaya yang belum intensif dan diperparah oleh keberadaan gulma yang dapat menimbulkan kerugian baik secara kualitas maupun kuantitas. Kerugian yang disebabkan oleh gulma perlu pengendalian dengan cara manual, selektif, dan ramah lingkungan salah satunya dengan penyiangan. Tujuan penelitian mengetahui besarnya pengaruh penyiangan yang dilakukan terhadap hasil tanaman wortel. Percobaan dilaksanakan di Desa Cikandang Lebak Kecamatan Cikajang Kabupaten Garut menggunakan Rancangan Acak Kelompok (RAK) dengan tujuh perlakuan dan empat kali ulangan menggunakan benih wortel kultivar lokal Cipanas Bogor. Karakter hasil yang diamati adalah Bobot Segar Daun per Tanaman, Bobot Kering Daun per Tanaman, Bobot Berangkasan per Tanaman, Bobot Bersih Umbi per Tanaman, Bobot Berangkasan per Petak, Bobot Bersih Umbi per Petak. Hasil penelitian menunjukkan siginifikan pada seluruh karakter yang diamati yaitu 10.22, $3.38,69.25,58.18,13.52,11.38$ penyiangan sebanyak tiga kali dan 10.26, 3.45, 71.48, 60.08, 13.72, 11.54 penyiangan sebanyak empat kali yang menunjukkan potensi hasil yang paling tinggi.

Kata Kunci :Wortel, Penyiangan, Hasil, Daucus carota L., Lokal Cipanas

Abstract. The potential of landraces in Indonesia as food needs have an important role. Carrot is one of vegetables which have an important role for human needed. Carrot as a source of vitamin A uses for cosmetic and drug consist of beta carotene. The low carrot productivity is caused by un-intensive cultivation moreover weed growth in cultivated area causes quality or quantity loss. One of solution to control weeds is by weeding. Weeding is able to controlled manually, selective and eco-friendly. The purpose of this study is to get the effect of weeding to carrot productivity. The experiment conducted in Cikandang village, Garut using Randomized Block Design (RBD) with seven treatments and four replicates using carrot landrace of Cipanas, Bogor. The yield characters consist of fresh leaf weight per plant, dry leaf weigh per plant, gross weight per plant, net tubers weight per plant, gross weight per plot, and 


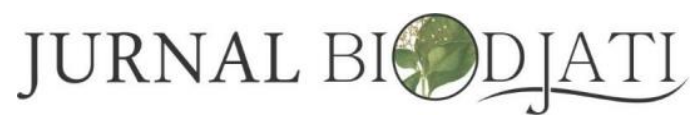

http://journal.uinsgd.ac.id/index.php/biodjati

net tubers weight per plot. The results showed significant in all characters observed i.e. 10.22, 3.38, 69.25, 58.18, 13.52, 11.38 for three times weeding and 10.26, 3.45, 71.48, 60.08, 13.72 in four times weeding that showed the highest yield potential.

Key words : Carrots, Weeding, Yields, Daucus carota L., Cipanas landrace

\section{Cara Sitasi}

Sobari, E., \& Fathurohman, F. (2017). Efektivitas Penyiangan Terhadap Hasil Tanaman Wortel (Daucus carota L.) Lokal Cipanas Bogor. Jurnal Biodjati, 2 (1), 1-8.

\section{PENDAHULUAN}

Wortel (Daucus carota L.) merupakan tanaman sayuran umbi biennial berbentuk semak. Sayuran jenis ini mudah dijumpai diberbagai tempat dan dapat tumbuh sepanjang tahun baik penghujan maupun kemarau. Wortel memiliki batang pendek yang hampir tidak tampak. Akarnya berupa akar tunggang yang berubah bentuk dan fungsi menjadi bulat dan memanjang. Tanaman wortel dapat tumbuh optimal di daerah bersuhu dingin atau berada dipegunungan dengan syarat ketinggian sekitar $1200 \mathrm{~m}$ dpl. Wortel mempunyai batang daun basah yang berupa sekumpulan pelepah pada tangkai daun yang muncul dari pangkal umbi bagian atas, yang mirip dengan daun seledri (Dwipoyono et al., 2012). Wortel merupakan nama umum yang diketahui seluruh masyarakat Indonesia. Sedangkan nama lokal dibeberapa wilayah seperti di daerah Jawa menyebutnya dengan "wertol atau wortol", khusus untuk di daerah Sunda disebut "bortol" sedangkan di masyarakat Madura menyebutnya "ortel".

Wortel merupakan jenis sayuran yang menyehatkan untuk tubuh manusia sehingga perlu dibudidayakan lebih banyak lagi untuk kesejahteraan dan memenuhi kebutuhan manusia. Selain enak dan digemari oleh banyak masyarakat sebagai bahan untuk membuat aneka macam masakan, wortel pula dapat digunakan sebagai bahan kosmetik serta berkhasiat obat sebagai penyembuh berbagai macam penyakit, karena di dalam umbi wortel mengandung senyawa beta karoten yang dapat menimbulkan kekebalan tubuh terhadap penyakit (Cahyono, 2002).

Konsumsi wortel dapat menurunkan kolesterol dan meningkatkan pencernaan karena mengandung unsur senyawa asam folat, asam pantotenat dan elemen penting lainnya $\mathrm{K}, \mathrm{Na}, \mathrm{Ca}, \mathrm{Mg}, \mathrm{P}, \mathrm{S}, \mathrm{Mn}, \mathrm{Fe}, \mathrm{Cu}$ dan $\mathrm{Zn}$ (Bystricka et al., 2015). Wortel sudah sangat dikenal tetapi banyak yang tidak tahu kandungan di dalam wortel selain vitamin A untuk kesehatan mata, selain itu wortel juga mengandung pigmen beta karoten. Kandungan beta karoten merupakan pigmen pemberi warna orange pada buah dan sayuran (Trianto et al., 2014). Karoten digunakan untuk beberapa senyawa yang berhubungan memiliki formula $\mathrm{C}_{40} \mathrm{H}_{56}$. Karotenoid terdapat di dalam kloroplas tanaman dan berperan sebagai katalisator dalam fotosintesis yang dilakukan oleh klorofil (Amiruddin, 2013). Jumlah beta karotein 100 gram tanaman wortel hibrida sebanyak 19.6 mg ( Karkleliene et al., 2012).

Menurut Rukmana (1995), Puslitbang Hortikultura dalam program penelitian dan pengembangan hortikultura di Indonesia wortel belum termasuk komoditas utama, baru dikategorikan komoditas potensial yang artinya mempunyai potensi yang baik. Akan tetapi selain bergizi tinggi wortel juga merupakan sayuran yang bernilai ekonomis, berdasarkan data pasar Jepang bernama Japan External Trade Organization (JETRO), ekspor 


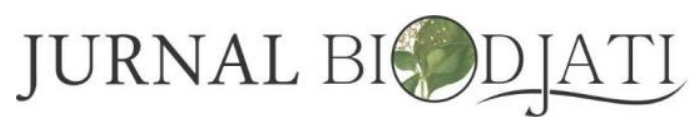

http://journal.uinsgd.ac.id/index.php/biodjati

wortel telah menjadi salah satu mata dagang komoditas pertanian antar negara. Di wilayah Jawa Barat varietas-varietas lokal Cipanas dan Lembang merupakan varietas yang baik (Sunaryono, 1980). Demikian pula menurut Adriani (1987), penampilan warna wortel varietas lokal Cipanas memiliki kriteria umbi berwarna jingga terang, bentuk umbinya cenderung silinder. Prospek pengembangan sayuran wortel lokal di Indonesia sangat cerah, karena didukung oleh keadaan agroklimatologi wilayah yang cocok untuk tanaman wortel.

Gulma merupakan salah satu tumbuhan pengganggu karena dapat mengganggu pertumbuhan dan perkembangan tanaman pokok sehingga produksi tanaman akan berkurang. Berkurangnya produksi ini diakibatkan karena adanya persaingan diantara tanaman pokok dengan gulma dalam hal tempat tumbuh, unsur hara, air, dan cahaya matahari. Jika hal tersebut dibiarkan maka proses penyerapan unsur hara dan air dalam tanah tidak dapat dilakukan, sehingga memberikan pengaruh besar terhadap tanaman karena tidak dapat melakukan fotosintesis. Gulma yang lebih tinggi dan lebih lebat daunnya, serta lebih luas dalam sistem perakarannya memiliki kemampuan bersaing yang lebih hebat, sehingga akan lebih menghambat pertumbuhan dan menurunkan hasil tanaman wortel. Akibat sistem perakaran wortel yang tidak dapat bekerja menyerap unsur hara dan air secara optimal, menyebabkan akar tanaman pokok pembentuk umbi tidak dapat berkembang baik. Karena kompetisi sumber hara, air dan cahaya yang dapat menimbulkan kerugian dalam produksi wortel baik secara kualitas dan kuantitas. Pengendalian gulma biasanya dilakukan secara manual menggunakan tangan atau alat sederhana dengan cara dicabut atau disiangi. Penyiangan dengan metoda seperti ini bertujuan agar tidak mengganggu perakaran tanaman wortel sebab umbi berkembang dari akar tunggang yang berubah bentuk dan fungsinya menjadi umbi bulat memanjang. Pertumbuhan gulma sangat cepat salah satu tindakan untuk mengendalikan gulma pada periode kritis tersebut dengan cara percobaan untuk mengetahui pengaruh penyiangan dengan berbagai interval terhadap pertumbuhan dan hasil tanaman wortel.

\section{BAHAN DAN METODE}

Percobaan ini dilaksanakan di Totall Cantigi Farm (TCF). Desa Cikandang Lebak. Kecamatan Cikajang Kabupaten Garut. Pada bulan Mei 2011 sampai September 2011. Lahan percobaan memiliki jenis tanah andosol dengan ketinggian tempat $1.250 \mathrm{~m}$ dpl. Lokasi percobaan bertipe curah hujan C (agak basah) berdasarkan Schmidt dan Ferguson (1951). Rancangan percobaan yang dipakai adalah Rancangan Acak Kelompok (RAK) yang terdiri dari tujuh perlakuan dengan empat kali ulangan. Perlakuan yang dicoba dalam percobaan ini terdiri dari kontrol tanpa penyiangan, satu kali penyiangan pada umur 20 HST, satu kali penyiangan pada umur 35 HST, satu kali penyiangan pada umur 50 HST, dua kali penyiangan pada umur 20 dan 35 HST, tiga kali penyiangan pada umur 20, 35, dan 50 HST, empat kali penyiangan pada umur 20, 35, 50, dan 65 HST. Luas petak percobaan $250 \mathrm{~cm}$ x $90 \mathrm{~cm}$, jarak antar petak $30 \mathrm{~cm}$, jarak antar ulangan $40 \mathrm{~cm}$. Penanaman menggunakan benih lokal Cipanas Bogor.

Karakter pengamatan pada percobaan ini terdiri dari Bobot Segar Daun per Tanaman (BSDT), rata-rata bobot segar daun dari tanaman sampel pada tiap petak percobaan penimbangannya dilakukan bersamaan pada saat panen. Bobot Kering Daun per Tanaman (BKDT) rata-rata bobot kering daun dari tanaman sampel pada tiap petak percobaan 


\section{JURNAL BIODJATI}

http://journal.uinsgd.ac.id/index.php/biodjati

penimbangannya setelah dikeringkan dalam oven pengering bertingkat pada temperatur 80 ${ }^{\circ} \mathrm{C}$ sampai konstan, Bobot Berangkasan per Tanaman (BBT) rata-rata bobot berangkasan per tanaman dari sampel pada tiap petak percobaan ditimbang bersamaan dengan daun, batang dan umbinya pada saat panen, Bobot Bersih Umbi per Tanaman (BBHUT) rata-rata bobot bersih umbi per tanaman dari sampel pada tiap petak percobaan, Bobot Berangkasan per Petak (BBP) rata-rata bobot berangkasan per petak dari tiap petak percobaan. Bobot Bersih Umbi per Petak (BBHUP) rata-rata bobot bersih umbi per petak dari tiap petak percobaan penimbangan dilakukan tanpa daunnya pada saat panen.
Analisis dan model linier dari percobaan ini adalah Gaspersz (1995) :

$$
X i j=U+t i+r j+e i j
$$

Keterangan :

$\mathrm{Xij}=$ Variabel yang diamati

$\mathrm{U} \quad$ = Rata-rata umum

ti $=$ Perlakuan ke-i

rj = Pengaruh kelompok ulangan ke-

eij = Pengaruh faktor random pada perlakuan ke-i dan ulangan ke-j

Dari model linier tersebut dapat disusun daftar analisis ragam seperti pada Tabel 1.

Tabel 1. Analisis Ragam

\begin{tabular}{lccccc}
\hline \multicolumn{2}{c}{ Sumber ragam } & $\mathrm{DB}$ & $\mathrm{JK}$ & $\mathrm{KT}$ & $\mathrm{Fh}$ \\
\hline 1. & Ulangan & $\mathrm{r}-1$ & $\mathrm{X}_{\mathrm{ij}}{ }^{2} / \mathrm{t}-\mathrm{X} . .^{2} / \mathrm{rt}$ & $\mathrm{KT}_{1}$ & $\mathrm{KT}_{1} / \mathrm{KT}_{3}$ \\
2. & Perlakuan & $\mathrm{t}-1$ & $\mathrm{X}_{\mathrm{ij}}{ }^{2} / \mathrm{r}-\mathrm{X} .{ }^{2} / \mathrm{rt}$ & $\mathrm{KT}_{2}$ & $\mathrm{KT}_{2} / \mathrm{KT}_{3}$ \\
3. & Galat & $(\mathrm{r}-1)(\mathrm{t}-1)$ & $(4)-(1)-(2)$ & $\mathrm{KT}_{3}$ & \\
\hline 4. & Total & $\mathrm{rt}-1$ & $\mathrm{X}_{\mathrm{ij}}{ }^{2} / 1-\mathrm{X} . .^{2} / \mathrm{rt}$ & & \\
\hline
\end{tabular}

Keterangan : $\mathrm{X}_{\mathrm{i}}=$ total perlakuan ke-i, $\mathrm{X}_{\mathrm{j}}=$ total kelompok ulangan ke-j, $\mathrm{X} . . .=$ total umum, $\mathrm{X}_{\mathrm{ij}}=$ angka pengamatan perlakuan ke-i dalam kelompok ke-j, DB = derajat bebas, JK= jumlah kuadrat, KT=kuadrat tengah (Peterson, 1994).

Apabila $\mathrm{F}$ hitung pada analisis ragam menunjukan keragaman nyata maka untuk menguji signifikan dilakukan uji lanjutan dengan menggunakan uji jarak berganda Duncan pada taraf nyata $5 \%$ dengan rumus sebagai berikut : $\operatorname{LSR}(\alpha, \mathrm{p}, \mathrm{dbG})=\operatorname{SSR}(\alpha, \mathrm{p}$, $\mathrm{dbG}) . \mathrm{S}_{\mathrm{x}}$

$$
\text { Dimana }: \mathrm{S}_{\mathrm{x}}=\sqrt{\frac{K T G}{r}}
$$

Keterangan :

$$
\begin{aligned}
& \text { LSR }=\text { Least Significant Ranges } \\
& \text { SSR }=\text { Studentized Significant Ranges } \\
& \mathrm{S}_{\mathrm{x}}=\text { Galat Baku rata-rata }
\end{aligned}
$$

$$
\begin{array}{ll}
\alpha & =\text { Taraf nyata } \\
\mathrm{dbG} & =\text { Derajat bebas galat } \\
\mathrm{p} & =\text { Jarak } \\
\mathrm{r} & =\text { Ulangan }
\end{array}
$$

HASIL

Hasil percobaan menunjukkan bahwa frekuensi penyiangan dapat meningkatkan penampilan karakter daya hasil tanaman wortel yang ditanam. Hal itu dapat dibuktikan dengan data yang diperoleh pada Tabel 2 berikut ini : 


\section{JURNAL BIODJATI}

http://journal.uinsgd.ac.id/index.php/biodjati

Tabel 2. Pengaruh Penyiangan Terhadap Karakter Penampilan Hasil

\begin{tabular}{|c|c|c|c|c|c|c|}
\hline \multirow{3}{*}{ Perlakuan } & \multicolumn{6}{|c|}{ Rata-rata } \\
\hline & BSDT & BKDT & $\mathrm{BBT}$ & BBHUT & BBP & BBHUP \\
\hline & gram & gram & Gram & Gram & $\mathrm{Kg} / 2,25 \mathrm{~m}^{2}$ & $\mathrm{Kg} / 2,25 \mathrm{~m}^{2}$ \\
\hline $\mathrm{A}=$ kontrol & $7,29 \mathrm{a}$ & $2,37 \mathrm{a}$ & $47,36 \mathrm{a}$ & $39.75 \mathrm{a}$ & $7,63 \mathrm{a}$ & $6,41 \mathrm{a}$ \\
\hline $\mathrm{B}=20 \mathrm{HST}$ & $8,69 \mathrm{~b}$ & $2,29 \mathrm{a}$ & $56,53 \mathrm{~b}$ & $47,48 \mathrm{~b}$ & $10,46 \mathrm{~b}$ & $8,79 \mathrm{~b}$ \\
\hline $\mathrm{C}=35 \mathrm{HST}$ & $9,19 \mathrm{c}$ & $3,09 \mathrm{~b}$ & $60,47 \mathrm{c}$ & $50,54 \mathrm{c}$ & $10,65 \mathrm{~b}$ & $8,96 \mathrm{~b}$ \\
\hline $\mathrm{D}=50 \mathrm{HST}$ & $9,29 \mathrm{~d}$ & $3,17 \mathrm{bc}$ & $59,59 \mathrm{~d}$ & $50,07 \mathrm{~d}$ & $10,50 \mathrm{~b}$ & $9,08 \mathrm{~b}$ \\
\hline $\mathrm{E}=20,35 \mathrm{HST}$ & $10,16 \mathrm{~d}$ & $3,36 \mathrm{~cd}$ & $68,34 \mathrm{e}$ & $57,40 \mathrm{e}$ & $13,26 \mathrm{c}$ & $11,13 \mathrm{c}$ \\
\hline $\mathrm{F}=20,35,50 \mathrm{HST}$ & $10,22 \mathrm{~d}$ & $3,38 \mathrm{~cd}$ & $69,25 \mathrm{f}$ & $58,18 \mathrm{f}$ & $13,52 \mathrm{~cd}$ & $11,38 \mathrm{~cd}$ \\
\hline $\mathrm{G}=20,35,50,65 \mathrm{HST}$ & $10,26 \mathrm{~d}$ & $3,45 \mathrm{~d}$ & $71,48 \mathrm{~g}$ & $60,08 \mathrm{~g}$ & $13,72 \mathrm{~d}$ & $11,54 \mathrm{~d}$ \\
\hline
\end{tabular}

Keterangan :

- $\quad$ HST = Hari Setelah Tanam, BSDT=bobot segar daun per tanaman, BKDT= bobot kering daun per tanaman, BBT= bobot berangkasan per tanaman BBHUT= bobot bersih umbi per tanaman, BBP= bobot berangkasan per petak dan BBHUP= bobot bersih umbi per petak.

- Angka rata-rata tiap perlakuan yang diikuti oleh huruf yang sama tidak berbeda nyata berdasarkan Uji Jarak Berganda Duncan pada Taraf $5 \%$.

Data yang ditunjukkan pada tabel 2, menjelaskan pengaruh banyaknya penyiangan yang dilakukan pada tanaman wortel terhadap penampilan hasil. Perbedaan nilai rata-rata tersebut dikarenakan adanya persaingan nutrisi dengan tumbuhan gulma yang sangat beragam sesuai dengan jenisnya. Karena pengaruh tersebut kompetisi yang terjadi mengakibatkan perbedaan hasil pada setiap perlakuan. Hal ini pula dipengaruhi oleh variasi gulma yang berbeda dengan kebutuhan nutrisi yang dibutuhkan berbeda pula. Gulma yang dominan tumbuh berdaun lebar seperti Amarantus sp, Oxalis curnikurata, Ageratum conyzoides. Berdasarakan penelitian Kilkoda et al. (2015) gulma Ageratum conyzoides dapat mempengaruhi komponen hasil, hal tersebut ditunjukkan pada parameter bobot 100 biji pada tanaman kedelai. Karena gulma Ageratum conyzoides merupakan salah satu dari sekian banyak gulma yang dapat menekan pertumbuhan tanaman budidaya. Selain itu keberadaan populasi gulma yang banyak menyebabkan tingkat penyerapan unsur hara dan adaptasi lingkungan memberikan respon yang buruk bagi pertumbuhan dan perkembangan tanaman wortel.

\section{PEMBAHASAN}

Pada karakter bobot segar dan bobot kering daun per tanaman memperlihatkan data yang signifikan pada setiap perlakuan dengan kontrol, hal ini menunjukkan akibat adanya persaingan sinar matahari antara tanaman pokok dengan gulma pada tanaman yang tidak disiangi atau frekuensi umur penyiangannya jauh. Mengakibatkan proses fotosintesis untuk menghasilkan karbohidrat terganggu. Hal ini seperti diungkapkan Edmond et al. (1957), bahwa tanaman wortel memiliki periode tumbuh pembentukan struktur penyimpanan diawali dengan perkembangan daun dan akar, untuk perkembangan daun dan akar dibutuhkan karbohidrat. Ketersediaan karbohidrat berkaitan dengan proses fotosintesis.

Keberadaan gulma yang menutupi tanaman wortel menyebabkan cahaya tidak dapat masuk dan menyebabkan keadaan sekitar titik tumbuh akan terjadi kelembaban yang terlalu tinggi menyebabkan stomata tertutup, sehingga penyerapan gas $\mathrm{CO}_{2}$ yang merupakan bahan baku dalam proses fotosintesis akan terhambat. Akibatnya, pertumbuhan dan pembentukan umbi menjadi 


\section{JURNAL BIODJATI}

http://journal.uinsgd.ac.id/index.php/biodjati

kurang baik (Samadi, 2014). Kelembaban yang diinginkan untuk pertumbuhan tanaman wortel berkisar $80-90 \%$. Kelembaban udara sangat dipengaruhi oleh ketinggian tempat dan curah hujan (Gustia, 2016).

Pada saat penjarangan pengaturan jarak tanam antara tanaman wortel diatur sedemikian rupa agar meminimalisir pertumbuhan gulma yang dapat bersaing dengan tanaman wortel dalam hal ruang tumbuh yang dapat menyebabkan persaingan antara akar gulma dalam penyerapan unsur hara dan cahaya matahari. Sehingga mengakibatkan kualitas umbi wortel tumbuh tidak optimal. Menurut Eprim (2006), pengaruh jarak tanam sangat erat hubungannya dengan penyerapan cahaya matahari sebagai sumber energi, sedangkan pengaturan jarak tanam yang berbeda akan menyebabkan perbedaan dalam tingkat kompetisi untuk mendapatkan cahaya dengan gulma menyebabkan pengaruh terhadap hasil tanaman.

Data karakter bobot berangkasan per tanaman dan bobot bersih umbi per tanaman (Tabel 2) menunjukkan frekuensi penyiangan dapat meningkatkan bobot umbi tanaman wortel. Hal ini disebabkan akibat kompetisi yang ditimbulkan oleh gulma pada saat awal muncul bisa mempengaruhi pertumbuhan dan perkembangan tanaman wortel. Hal ini sesuai dengan percobaan yang dilakukan Septrina (2008) terhadap kompetisi pertumbuhan gulma akan mulai bersaing dengan tanaman mulai 36 MST. Begitu pula karakter pengamatan pada bobot berangkas dan bobot bersih umbi per tanaman dicapai oleh perlakuan penyiangan sebanyak empat kali yaitu pada umur 20, 35, 50 dan 65 HST (Perlakuan G) mengalami peningkatan yang signifikan dibandingkan kontrol dan karakter pengamatan lainnya disebabkan penyiangan yang lebih banyak menurunkan tingkat kompetisi gulma dan tanaman budidaya menyebabkan tanaman wortel dapat berkembang secara optimal. Menurut Adriani (1987) menyatakan bahwa pada umur panen yang optimum, umbi segar varietas lokal Cipanas memiliki bobot segar antara 58 gram sampai dengan 76 gram dengan diameter pangkal dan panjang kurang lebih 3-13 cm. Perbedaan bobot tersebut diperlihatkan oleh karakter pengamatan perlakuan C, D, E, F yang menunjukkan berbeda nyata pada setiap perlakuannya.

Tumbuhnya gulma dikarenakan adanya pengaruh lingkungan yang sesuai sehingga menyebabkan gulma cepat tumbuh. Pengaruh tersebut meliputi suhu, keadaan air, intensitas cahaya, angin, landscape, dan waktu. Pada data bobot berangkasan per petak dan bobot bersih umbi per petak pada tabel 2 menunjukkan Peningkatan pada perlakuan tiga kali dan empat kali penyiangan (perlakuan $\mathrm{F}$ dan G), karena pertumbuhan gulma sudah dapat ditekan pertumbuhannya pada tingkat minimun yaitu pada umur 20, 35, dan 50 HST (Perlakuan F). Pada tingkat ini gangguan gulma terhadap tanaman wortel dapat diminimalisir dari segi kompetisi yang dapat mempengaruhi hasil. Berdasarkan hasil data persentasi penutupan gulma pada setiap perlakuan menunjukkan rata-rata berkisar 33,68\%- 39,81\% (perlakuan B, C, D) 23,25 \%- 29,31 \% (Perlakuan E, F, G) dan 60,12\% pada kontrol (Perlakuan A) (data lengkap tidak disajikan). Tanaman yang tumbuh pada lingkungan yang gangguan penutupan gulmanya lebih banyak akan terpengaruhi pertumbuhannya sehingga produksi yang dihasilkan pada akhirnya akan rendah. Hal ini disebabkan oleh kurang adanya keseimbangan antara kebutuhan energi untuk fotosintesis yang diperlukan dengan unsur yang menunjang seperti CO2, unsur hara, dan cahaya. Beberapa spesies gulma seperti kelompok Cyperus yang tumbuh disekitar 


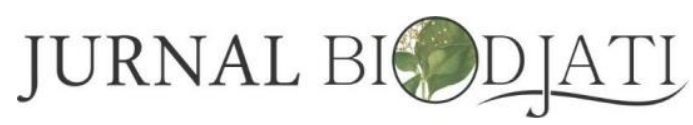

http://journal.uinsgd.ac.id/index.php/biodjati

tempat penanaman, ternyata memberikan dampak pada penurunan jumlah anakan dan bobot kering tanaman padi (Septrina, 2008). Hal tersebut menegaskan bahwa dominansi gulma di lapangan turut mempengaruhi hasil tanaman wortel.

Hasil percobaan interval penyiangan berpengaruh terhadap hasil tanaman wortel untuk tiap taraf penyiangan. Hal ini terjadi akibat adanya persaingan antara tanaman dengan gulma dalam hal memperebutkan unsur hara, air, sinar matahari dan ruang tumbuh. penyiangan 3 kali dan 4 kali berpengaruh nyata terhadap hasil wortel yang paling tinggi. Penyiangan sebanyak 3 kali dapat direkomendasikan kepada para petani dalam budidaya tanaman wortel.

\section{DAFTAR PUSTAKA}

Adriani, N. (1987). Pertumbuhan dan Perkembangan Wortel Varietas Lokal Cipanas. Skripsi. Bogor: Jurusan Budidaya Pertanian. Fakultas Pertanian. Institut Pertanian Bogor. No. 951-1 Hal. 5-8.

Amiruddin, C. (2013). Pembuatan Tepung Wortel (Daucus carrota L) dengan Variasi Suhu Pengering. Skripsi. Makasar : Program Studi Teknik Pertanian. Universitas Hasanuddin.

Bystricka, J., Kavalcova, P. Musilova, J. Vollmannova, A., Toth, T., \& Lenkova, M. (2015). Carrot (Daucus carota L. ssp. sativus (Hoffm.) Arcang.) as source of antioxidants. Acta agriculturae Slovenica, $105-2$.

Cahyono, B. (2002). Wortel "Teknik Budidaya dan Analisis Usaha Tani”. Kanisius. Yogyakarta.

Dwipoyono, H.S., Tyasmoro, S.Y., \& Nugroho, A. (2012). Pertumbuhan dan Hasil Tanaman Wortel (Daucus carota L.) yang Ditanam Tumpang Sari Dengan
Tanaman Apel (Malus sylvestris MILL) Dengan Arah Bedengan Berbeda Di Lahan Miring.

Edmond, J. B., Musser, A. M., \& Andrews, F.S. (1957). Fundamental of Horticulture. Mc Graw Hill Book co. Inc. New York. 456 p.

Eprim, S. Y. (2006). Periode Kritis Tanaman Kedelai (Glycine max (L.) Merr) Terhadap Kompetisi Gulma Pada Beberapa Jarak tanam di Lahan Alang-alang (Imprata cylindrica (L.) Beauv.). Skripsi. Bogor : Program Studi Agronomi, Fakultas Pertanian. Institut Pertanian Bogor.

Gaspersz, V. (1995). Teknik Analisis dalam Penelitian Percobaan. Edisi Pertama. Tarsito: Bandung. HIm. 124-148.

Gustia, H. (2016). Respon Tanaman Wortel Terhadap Pemberian Urine Kelinci. Jurnal Agrosains dan Teknologi, Vol. 1 No. 1 Juni 2016. Hal 46-55.

Karkleliene, R., Radzevicius, A., Dambrauskiene, E., Surviliene, E. Bobinas, C. Duchovskiene, L Kavaliauskaite, D., \& Bundiniene, O. (2012). Root yield, quality and disease resistance of organically grown carrot (Daucus sativus Röhl.) hybrids and cultivars. Agriculture, vol. 99, No. 4, 393$398 \mathrm{p}$.

Kilkoda, A.K., Nurmala, T., \& Widayat. (2015). Pengaruh Keberadaan Gulma (Ageratum conyzoides dan Boreria alata) Terhadap Pertumbuhan dan Hasil Tiga Ukuran Varietas Kedelai (Glycine max L. Merr) Pada Percobaan Pot Bertingkat. Jurnal Kultivasi, Vol. 14 (2) : 1-9.

Peterson, R. G. (1994). Agricultural field Experiments Design and Analysis. Oregon State University. Marcel Dekker, Inc. 48$53 \mathrm{p}$.

Rukmana, R. (1995). Bertanam Wortel. Kanisius. Yogyakarta. 


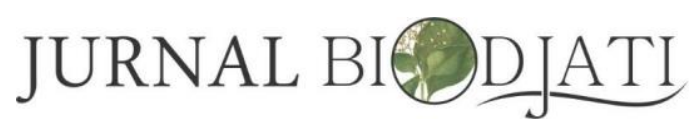

http://journal.uinsgd.ac.id/index.php/biodjati

Samadi, B. (2014). Rahasia Budidaya Wortel Sistem Organik. Pustaka Mina. Depok.

Schmidt, F. H., \& Ferguson, J. H. A. (1951). Rainfall Types Based On Wet and Dry Period Rations for Indonesia With Western New Guinea. Jakarta: Kementrian Perhubungan Meteorologi dan Geofisika.

Septrina, G. (2008). Pengaruh Waktu dan Cara Pengendalian Gulma Terhadap Pertumbuhan dan Hasil Padi Hibrida (Oryza sativa L.). Skripsi. Bogor : Program Studi Agronomi. Institut Pertanian Bogor.

Sunaryono, H. (1980). Kunci Bercocok Tanam Sayur-sayuran Penting di Indonesia. Badan Penelitian dan Pengembangan Pertanian. Lembaga Penelitian Hortikultura. Pasar Minggu. Jakarta.

Trianto, S., Lestyorini, S.Y., \& Margono. (2014). Ekstraksi Zat Warna Alami Wortel (Daucus Carota) Menggunakan Pelarut Air. Ekuilibrium, Vol. 13. No. 2. ISSN : 1412-9124. Hlm. 51 - 54. 